\title{
Survival after cytotoxic chemotherapy in patients with advanced hormone-resistant prostate cancer: A phase II study
}

\author{
GEORGE P. STATHOPOULOS ${ }^{1}$, JOHN KOUTANTOS ${ }^{1}$, MICHAEL M. VASLAMATZIS ${ }^{2}$, \\ ATHANASIOS ATHANASIADIS ${ }^{3}$, GEORGE PAPADOPOULOS ${ }^{1}$, G. LABRODIMOU $^{1}$, \\ JOHN STATHOPOULOS ${ }^{1}$ and SOTIRIS RIGATOS ${ }^{1}$ \\ ${ }^{1}$ First Oncology Department, Errikos Dunant Hospital; ${ }^{2}$ Oncology Department, Evangelismos Hospital, Athens; \\ ${ }^{3}$ Oncology Department, General Hospital, Larissa, Greece.
}

Received February 12, 2009; Accepted April 8, 2009

DOI: $10.3892 /$ or_00000443

\begin{abstract}
In the past, it was believed that when advancedstage prostate cancer became resistant to hormonal management, no chemotherapy should be administered, as survival was not prolonged. Mitoxanthrone and prednisone were mostly administered, while recently, other agents such as docetaxel or paclitaxel have been tested both with and without hormonal treatment. The objective of the present phase II study was to determine the survival and the response rate of patients after the chemotherapy was administered. Sixty-five patients with advanced prostate cancer were included. The inclusion criteria involved histological confirmation of adenocarcinoma and resistance to hormonal therapy. The majority of the patients had stage IVa or IVb disease and a performance status of $0-1$ to 2 . The treatment involved chemotherapy in combination with a luteinizing hormone-releasing hormone (LHRH) or dexamethasone or estramustine. The hormone treatment preceded the cytotoxic administration and no amelioration in the patients nor prostate serum antigen (PSA) reduction was observed. The initial cytotoxic agents administered were docetaxel $75 \mathrm{mg} / \mathrm{m}^{2}$ in 25 patients, mitoxanthrone $10 \mathrm{mg} / \mathrm{m}^{2}$ in 15 patients, epirubicin $75 \mathrm{mg} / \mathrm{m}^{2}$ in 15 patients and paclitaxel $175 \mathrm{mg} / \mathrm{m}^{2}$ in 10 patients, all repeated every 3 weeks. The response rate was documented by bone scan, CT scan of the abdomen (and occasionally of the chest) and by the PSA serum value. Clinical benefit was also estimated. Thirty-three $(50.77 \%)$ patients achieved a partial response; stable disease was observed in $24(36.92 \%)$ patients and disease progression in $8(12.31 \%)$. Twenty-two $(33.85 \%)$ experienced clinical benefit. A significant PSA reduction was seen in $35(53.85 \%)$ patients. The median survival was 18 months and the range 3-84 months. One, 2, 3 and fiveyear survival was $75.38,23.07,12.30$ and $4.66 \%$, respectively.
\end{abstract}

Correspondence to: Dr G.P. Stathopoulos, Semitelou 2A, 11528 Athens, Greece

E-mail: dr-gps@ath.forthnet.gr

Key words: chemotherapy, prostate cancer
Toxicity was well-tolerated. Patients with hormone-resistant advanced prostate cancer do have good prospects for receiving substantial benefit with the addition of chemotherapy, as observed in the present trial.

\section{Introduction}

Chemotherapy has been used sporadically for a long period of time in patients with advanced prostate cancer (1). Survival benefit has recently been reported; certain selected agents have been used in randomized trials to determine the effectiveness of chemotherapy and the prolongation of survival. The cytotoxic agents, mitoxanthrone and docetaxel, are those which have mainly been tested.

Several other agents have shown effectiveness, but none of these have been considered as standard care (1). Anthracyclines cyclophosphamide, 5-flouorouracil, etoposide, cisplatin and analogues, and vinca alkaloids are some of the agents which have been tested in prostate cancer, refractory to hormonotherapy. The data related to chemotherapeutical use in prostate cancer have been discussed and the beneficial outcome has been debated (2). Also, it is difficult to define the response in patients with bone metastases. What remains as objective targets are the prolongation of survival and the quality of life.

One of the most commonly used cytotoxic agents was, and is, mitoxanthrone. A study which compared treatment with hydrocortisone with or without mitoxanthrone showed no difference in overall survival (12.3 and 12.6 months) between the two groups, but did show that treatment failure was delayed when the combination was administered (3). There are some data reporting the use of other agents, single or in combination, which mainly target survival prolongation and improvement of the quality of life.

The primary objective of the present phase II study was to determine patient survival and the secondary objective, the response to chemotherapy.

\section{Patients and methods}

Eligibility for the study required the following: histologically confirmed carcinoma of the prostate pretreated with hormonal 
antiandrogen agents, in patients with advanced stage disease and with disease progression, while under hormonal treatment; disease staging with measurable or evaluable disease by X-rays, ultrasound or computer tomography (CT) scan, physical examination, World Health Organization (WHO) performance status of $0-2$, expected survival $\geq 12$ weeks, adequate bone marrow, reserve/leukocyte count $\geq 3500 / \mu 1$, platelet count $\geq 100,000 / \mu 1$ and hemoglobin $\geq 10 \mathrm{~g} / \mathrm{dl}$, adequate renal function (serum creatinine $\leq 1.5 \mathrm{mg} / \mathrm{dl}$ ) and liver function (serum bilirubin $\leq 1.5 \mathrm{mg} / \mathrm{dl}$ ) and serum transaminases $\leq 3$ times the normal upper limit [or $\leq 5$ times the upper normal limit in cases of liver metastases], and age $\geq 18$ years. Asymptomatic brain metastases were not excluded. This study was conducted with the approval of our institutional review board.

Baseline and treatment assessment and evaluation. Before study entry, all patients underwent the following evaluations: physical examination, tumor measurement or evaluation, WHO performance status, ECG, full blood count, liver and kidney function tests and urinalysis. Staging was determined by chest and abdominal CT scans, bone scan and occasional magnetic resonance imaging. Blood count, blood urea and serum creatinine were measured before each treatment administration and 7 days after treatment. During the treatment period, radiologic tests were conducted in case of clinical signs of disease progression. Prostate serum antigen (PSA) was examined once per month or earlier in cases of disease progression.

Response data were based on the response evaluation criteria in solid tumors (RECIST) (4). A complete response (CR) was considered to be the disappearance of all measurable disease confirmed at 6-8 weeks at the earliest and a partial response (PR), a $30 \%$ decrease of the tumor burden also at 6-8 weeks at the earliest, after completion of 4-6 courses of treatment. In stable disease (SD) neither PR nor progressive disease (PD) criteria were met and in PD, a $20 \%$ increase or more of tumor burden and no CR, PR, or SD were documented before increased disease. A $>10 \%$ loss of weight at pretreatment or increasing symptoms did not by themselves constitute disease progression, however, the appearance of these complaints was followed by a new evaluation of the extent of the disease. PSA was also used as an evaluation criterion. Toxicity was assessed using standard WHO criteria. The determination of objective response on computed tomography was performed by two independent radiologists and two experienced oncologists.

Treatment plan. All patients had been treated with antiandrogen-hormonal treatment before they began chemotherapy. Disease progression and PSA increase while the patients were on hormonal treatment signalled the hormone-resistant patients. Three oncology clinics contributed to the study. The initial cytotoxic drug selection was not the same in all the participants. Twenty-five patients were treated with docetaxel $75 \mathrm{mg} / \mathrm{m}^{2}$ once every 3 weeks and estramustine $700 \mathrm{mg}$ daily for a minimum of 6 cycles. Fifteen patients were treated with mitoxanthrone $10 \mathrm{mg} / \mathrm{m}^{2}$ once every 3 weeks and estramustine $700 \mathrm{mg}$ daily for a minimum of 6 cycles. This estramustine dose was reduced to 420 or even $280 \mathrm{mg}$ in cases of gastritis. Fifteen patients were treated with epirubicin (3 of whom
Table I. Patient characteristics.

\begin{tabular}{lcc}
\hline & No. & $(\%)$ \\
\hline Enrolled & 65 & $(100)$ \\
Evaluable & 65 & $(100)$
\end{tabular}

$\begin{array}{lc}\text { Age (yrs) } & \\ \text { Median } & 69 \\ \text { Range } & 49-82\end{array}$

Histology

Adenocarcinoma $\quad 65$

Differentiation

Medium

Low

Stage of disease

III 5

IVa 14

$\mathrm{IVb}$

Performance status

$0-1 \quad 42$

2

Metastatic site

Locoregional 5

Pelvis lymphadenopathy $\quad 14$

Bone metastasis

Liver or brain

40

Previous treatment

LHRH + antiandrogen

65

received doxorubicin) $75 \mathrm{mg} / \mathrm{m}^{2}$ every 3 weeks combined with low-dose prednisolone or dexamethasone for several days or continuously until disease progression. As initial cytotoxic treatment, ten patients received paclitaxel $175 \mathrm{mg} / \mathrm{m}^{2}$ every 3 weeks. Seven of the above 10 patients received paclitaxel combined with cisplatin $75 \mathrm{mg} / \mathrm{m}^{2}$ every 3 weeks. Premedication included ondasetron $8 \mathrm{mg}$ i.v. and dexamethasone $8 \mathrm{mg}$ i.v. before and at the end of the treatment. Ten patients with disease progression and who had not been previously treated with mitoxanthrone underwent second-line treatment with this agent $\left(10 \mathrm{mg} / \mathrm{m}^{2}\right) ; 14$ patients received vinorelbine at a dose of $25 \mathrm{mg} / \mathrm{m}^{2}$. The total number of courses was 520, median, 8 courses. Patient evaluation for response was done by bone scan, CT scan of the abdomen (and occasionally of the chest) and by the PSA value.

Toxicity. Most of the patients tolerated the treatment well without any postponement or dose reduction. The majority of the patients $(50,76.92 \%)$ had grade 1-3 anemia over the courses of treatment. Myelotoxicity with grade 1-3 neutropenia was seen in $15(23.08 \%)$ patients. Granulocyte growth factor was given to $5(7.69 \%)$ patients. Gastritis (nausea/ vomiting and diarrhea) was observed but it was uncommon. 
Table II. Results of treatment.

\begin{tabular}{lcc}
\hline & No of patients & $\%$ \\
\hline Response (PR) & 33 & 50.77 \\
Stable disease (SD) & 24 & 36.92 \\
Progressive disease (PD) & 8 & 12.31 \\
Clinical benefit (pain reduction) & 22 & 33.85 \\
\hline
\end{tabular}

\section{Results}

Sixty-five patients were included in the study between 2000-2007 and all were evaluable for toxicity, response and survival. The patient characteristics are shown in Table I. The median age was 69 years (range 49-82). The great majority of the patients $(60,92.31 \%)$ were stage IVa or IVb. The WHO performance status was 0-2. All patients underwent hormone treatment before entering the chemotherapy trial; this treatment was a luteinizing hormone-releasing hormone (LHRH) injection every 28 days plus antiandrogen tablets given daily. All patients had histologically confirmed adenocarcinoma. The dose intensity of the treatment was $92 \%$.

Response. An objective response rate was observed in 33 patients $(50.77 \%)$. No complete response was seen as all the above patients achieved a partial response. Stable disease was seen in 24 patients $(36.92 \%)$ and disease progression in 8 patients $(12.31 \%)$. Twenty-two patients $(33.85 \%)$ experienced clinical benefit, mainly expressed by pain reduction. The serum level of PSA was important in evaluating the response: $35 / 65(53.85 \%)$ patients had a PSA level reduction of $>50 \%$. The median duration of progression-free survival was 7 months and the range 4-17 months. Table II shows the response rate. The second-line treatment did not seem to have a major effect on survival as only 2 patients achieved a further response.

Survival data. The median follow-up was 36 months, minimum 12 and maximum 84 months. The median survival was 18 months and the range 3-84 months (CI 95\% 16-20). The mean survival was 24 months (CI 95\% 19-30). The 1-year survival was $75.38 \%$, 2-year $23.07 \%$, 3-year $12.30 \%$ and 5 -year $4.66 \%$. Fig. 1 shows the Kaplan-Meier survival curve and Table III shows the survival data.

\section{Discussion}

It appears that the present trial confirms the effectiveness of chemotherapy with cytotoxic agents in cancer patients refractory to hormonal manipulation. The past belief that chemotherapy may only have a beneficial effect no longer stands. The cytotoxic agent that has been shown to have superior effectiveness is docetaxel. A trial that compared docetaxel plus prednisone vs. mitoxanthrone plus prednisone in advanced prostate cancer patients showed the median survival of the docetaxel group was 18.9 months while in the mitoxanthrone group it was 16.5 months (5). These researchers also reported that the reduction of the PSA level ranged from

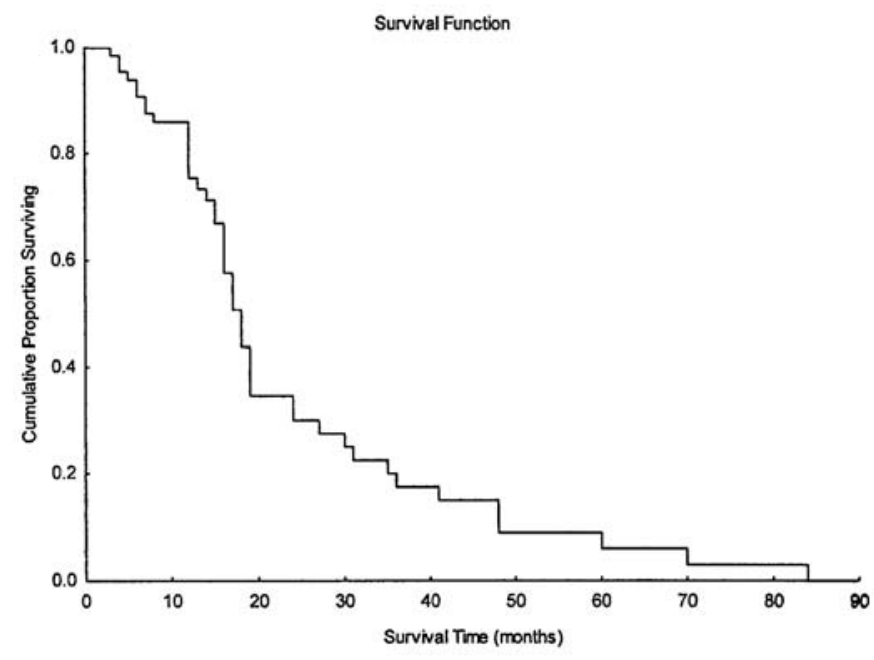

Figure 1. Kaplan-Meier survival curve.

Table III. Survival.

\begin{tabular}{lc}
\hline Median survival & 18 months (CI 95\% 16-20) \\
Range & $3-84$ months \\
Progression-free survival & \\
Median & 7 months \\
Range & $4-17$ months \\
\hline
\end{tabular}

45-48\%. Another trial compared docetaxel plus estramustine vs. mitoxanthrone plus prednisone in patients with advanced prostate cancer (6). It was also found that the group of patients who received docetaxel and estramustine had a superior median survival (17.5 months) whereas the median survival was 15.6 months in the group that received mitoxanthrone

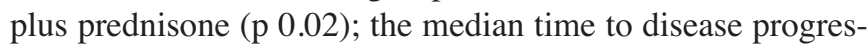
sion was 6.3 months vs. 3.2 months, respectively. Whether the addition of estramustine in group one, vs. the addition of prednisolone in group two, was what made the difference, cannot be clarified. Other data supporting the effectiveness of mitoxanthrone have been documented (7). There are also data predicting patient survival when the disease is refractory to hormonal treatment (8). The combination of docetaxel and antiandrogens or calcitriol is also effective (9-10). It has been suggested that the combination of docetaxel with thalidomide is an effective therapy (11). The sequential administration of docetaxel and mitoxantrone without defining which of the two agents should be given first, has also been discussed (12). A new cytotoxic agent, ixabepilone, has also shown efficacy in patients with advanced prostate cancer (13).

It was not the intention of our study to show which of the cytotoxic agents used, was more or less effective. Mitoxantrone has been tested before $(3,7)$ and it is one of the agents to be selected for administration for prostate cancer. Docetaxel has also recently been advocated for advanced hormone-resistant prostate cancer $(10,12)$. The objectives of the present study were to determine patient survival and response to chemotherapy. A good quality of life was observed in $3 / 4$ of the patients who survived over one year. 
In conclusion, our study shows similar results to some recent studies in the literature with respect to response rate and survival. This present study confirms the value of cytotoxic agents in patients with advanced prostate cancer, refractory to hormonal manipulation.

\section{References}

1. Zelofsky MJ, Eastham JA, Sartor OA and Kantoff P: Cancer of the prostate. In: Cancer Principles and Practice of Oncology. 8th edition. DeVIta VT, Laurence TS and Rosenberg SA (eds). Lippincott, Williams and Wilkins, Philadelphia, pp1392-1452, 2008.

2. Fossa S, Aarouson N and Newling D: Quality of life and treatment of hormone-resistant prostate cancer. Eur J Cancer 26: 1133-1136, 1990.

3. Kantoff PW, Halabi S, Conaway M, Picus J, Kirshner J, Hars V, Trump D, Winer EP and Vogelzang NJ: Hydro-cortisone with or without mitoxanthrone in men with hormone-refractory prostate cancer: results of the cancer and leukemia group B 9182 study. J Clin Oncol 17: 2506-2513, 1999.

4. Teresse P, Arbuck SG, Eisenhawer EA, Wanders J, Kaplan RS Rubintein L, Verweij J, van Glabbeke M, van Oosterom AT, Christian MC and Gwyther SG: New guidelines to evaluate the response to treatment in solid tumors. J Natl Cancer Inst 92: 205-216, 2000

5. Tannock IF, de Wit R, Berry WR, Horti J, Pluzanska A, Chi KN, Oudard S, Theodore C, James ND, Turesson I, Rosenthal MA and Eisenberger MA: TAX 327 Investigators: docetaxel plus prednisone or mitoxanthrone plus prednisone for advanced prostate cancer. N Engl J Med 351: 1502-1512, 2004.

6. Petrylak DP, Tangen CM, Hussain MH, Lara PN, Jones JA, Taplin ME, Burch PA, Berry D, Moinpour C, Kohli M, Benson MC, Small E, Raghowan D and Crawford D: Docetaxel and estramustine compared with mitoxanthrone and prednisone for advanced refractory prostate cancer. N Engl J Med 351: 1513-1520, 2004.

7. Tannock IF, Osoba D, Stockler MR, Ernst SD, Neville AJ, Moore MJ, Armitage GR, Wilson JJ, Venner PM, Coppin CML and Murphy KC: Chemotherapy with mitoxanthrone plus prednisone or prednisone alone for symptomatic hormoneresistant prostate cancer: a Canadian randomized trial with palliative end points. J Clin Oncol 14: 1756-1764, 1996.
8. Halabi S, Small EJ, Kantoff PW, Kuttan MW, Kaplan EB, Dowson NA, Levine EG, Blumenstein BA and Vogelzang NJ: Prognostic model for predicting survival in men with hormonerefractory metastatic prostate cancer. J Clin Oncol 21: 1232-1237, 2003.

9. Moore CN, Creel P, Petros W, Torain T, Yenser S, Gockerman J, Hurwitz H, Turner G, Sleep DJ and George DJ: Phase I-II study of docetaxel and atrasentan in men with metastatic hormonerefractory prostate cancer. 2005. ASCO Annual Meeting Proceedings Part. I. J Clin Oncol 24 (Suppl. 18): S14504, 2006.

10. Beer TM, Ryan CW, Venner PM, Petrylak DP, Chatta G, Ruether JD, Redfern CH, Fehrenbacher L, Saleh MN, Waterhouse DM, Carducci MA, Vicario D, Dreicer R, Higano CS, Ahmann FR, Chi KN, Henner WD, Arroyo A and Clow FW: Double-blinded randomized study of high-dose calcitriol plus docetaxel compared with placebo plus docetaxel in androgenindependent prostate cancer: a report from ASCENT Investigators. J Clin Oncol 25: 669-674, 2007.

11. Dahut WL, Gulley JL, Arlen PM, Liu Y, Fedenko KM, Steinberg SM, Wright JJ, Parnes H, Chen CC, Jones E, Parker CE, Linehan WM and Figg WD: Randomized phase II trial of docetaxel plus thalidomide in androgen-independent prostate cancer. J Clin Oncol 22: 2532-2539, 2004.

12. Michels J, Montemurro T, Murray N, Kollmannsberger C and Nguyen CHIK: First- and second-line chemotherapy with docetaxel or mitoxanthrone in patients with hormone-refractory prostate cancer: does sequence matter? Cancer 106: 1041-1048, 2006.

13. Rosenberg JE, Weinberg VK, Kelly WK, Michaelson D, Hussain M, Wilding G, Gross M, Hutcheon D and Small EJ: Activity of second-line chemotherapy in docetaxel refractory hormone-refractory prostate cancer patients: randomized phase 2 study of ixabepilone or mitoxanthrone and prednisone. Cancer 110: 556-563, 2007. 